\title{
A Brief Analysis of the Humanistic Thinking in the Communist Manifesto
}

\author{
Huaying Wang \\ School of Marxism, Lianyungang Normal College, Lianyungang, China \\ Email: 2270115847@qq.com
}

How to cite this paper: Wang, H.Y. (2022) A Brief Analysis of the Humanistic Thinking in the Communist Manifesto. Open Access Library Journal, 9: e8318.

https://doi.org/10.4236/oalib.1108318

Received: December 23, 2021

Accepted: January 17, 2022

Published: January 20, 2022

Copyright ( 2022 by author(s) and Open Access Library Inc.

This work is licensed under the Creative Commons Attribution International License (CC BY 4.0).

http://creativecommons.org/licenses/by/4.0/

\section{(c) (i) Open Access}

\begin{abstract}
The Communist Manifesto (hereinafter referred to as the Manifesto) is a programmatic document of the international Communist Movement. It marks the birth of Marxism, and is one of the most far-reaching works on the social transformation and ideological revolution of human beings, which contains rich humanistic thinking. On the basis of understanding the creation background of the Declaration, this paper deeply explores the text's emphasis on human nature and its concern for the free and comprehensive development of human beings, and considers the specific application of Marxist humanistic thinking in China. These will provide important practical inspiration for China's current development, open up a path of Modernization with Chinese characteristics in an innovative way, and inspire the cause of socialism with Chinese characteristics to make new leaps.
\end{abstract}

\section{Subject Areas}

Anthropology

\section{Keywords}

The Communist Manifesto, Liberation of Humanity, Free Development, Chinese-Style Modernization, Time Value

\section{一、引言}

《共产党宣言》(简称《宣言》) 的问世预示着无产阶级的革命者从此有 了科学理性的世界观去认识世界、改造世界, 是世界各国无产阶级解放运动 的指南, 是无产阶级战胜资产阶级的重要思想武器, 归根到底是全人类最终 解放、自由发展的伟大旗帜。“全人类的自由解放和全面发展” 是《宣言》 
的主旨所在, 这也是马克思主义人学思维在本书中的最终归宿。不同于《德 意志意识形态》中 “人学” 的片面性和抽象性, 《宣言》更加关注人的现实 性, 将理论运用当人的实际生活中去, 从更广泛的层面去分析人性、人的价 值及人的自由解放。本文立足于新时代的大背景全面诠释《宣言》蕴涵的人 学思想, 主要从文本的创作背景、人学思维的基本内容、人学思维的当代价 值这三个方面着手, 进一步探究马克思人学思维在本阶段的先进性, 继而为 中国式现代化发展提供新的思路。

\section{二、《宣言》的创作背景}

任何一种理论思维的出现都不是凭空而来的, 都是建立在特定的社会条 件基础上的。《宣言》是国际共产主义运动的第一个纲领性文件, 是马克思 在理论研究和理论斗争中形成的科学性产物。该著作的出现绝不是偶然现象, 而是在丰富的时代背景下必然产生的理论成果。

\section{(一) 经济发展背景}

物质决定意识, 一种思想理论的诞生必定深受那个时代的经济物质发展 的影响。19 世纪的经济不断出现新的发展形式, 特别是资本主义社会生产形 式的改变导致很多社会矛盾的激化。资本主义社会化大生产，严重影响民众 参与生产的积极性，资本主义经济的发展也遭到破坏，由此也日益暴露出资 本主义不可避免的短板。这些经济领域的问题是马克思主义产生的物质经济 条件, 也是推动《宣言》问世的重要经济动力。

第一次工业革命促使了社会经济的高度发展, 当时已经初步完成工业革 命的西欧各国已经在本国内建立起资本主义制度。随伴着资产阶级发展势头 日益迅猛, 社会逐渐出现了与之对立的工人阶级。特别是 1825 年的经济危机, 更是进一步激化了已有的社会矛盾, 工人运动愈发激烈。作为一个新生的阶 级, 严重缺乏经验的工人阶级在运动中屡屡碰壁, 在反对资产阶级、计划缓 和社会矛盾的活动中充满曲折。面对现实问题, 马克思开始从理论层面为加 速工人运动继续向前探寻新的出路。由此，他们立足于现实处境投身到大量 的理论研究中, 在深刻批判了空想社会主义不足的基础上完成了《宣言》的 写作，国际工人运动从此有了科学的真理性指导。

\section{（二）政治运动背景}

经济是政治的基础，经济领域矛盾的激化势必导致政治运动充斥着更为 激烈的斗争。 《宣言》正是在政治运动的催生中出现的： “欧洲三大工人运 动” 就是影响《宣言》创作最重要的政治因素之一。该运动爆发于 19 世纪 30 40 年代, 《宣言》正是在 19 世纪的 40 年代正式问世, 这就表达了 “工 人运动” 的政治现实对理论的形成有不可替代的鼓动作用。“三大运动” 催 促欧洲的无产阶级开始登上历史舞台，并在历史纵向发展的继承中扮演着更 加突出的角色。实际上, “三大运动” 没有达到预想的革命效果, 活动的结 果也很残酷, 与无产阶级的诉求仍有较大的距离。但正是运动的失败和带来 
的负面影响, 才传达了工人阶级要取得革命的胜利必须要䢃波斩浪的信号。 另一方面, 无产阶级想最终掌握政治的领导权力, 就必须要有正确的思想观 念保驾护航, 形成满足自己阶级需要的理论支撑; 同时也需要通过暴力运动 提高自己的威慑力，实现无产阶级的政治统治。

无产阶级通过持续组织独立的政治运动, 逐步体会到要想推翻资产阶级 的专制就必须明确自己的历史地位和历史任务，掌握资本主义制度究竟是一 种什么样的制度, 以及究竟如何去推翻这一制度, 从而实现自身的解放。换 言之, 创造一种强有力的科学理论指导具体的政治运动, 才是无产阶级最为 迫切的现实需要。以上这些因素也再次从政治支撑和阶级基础层面呼唤《宣 言》的横空出世, 为马克思主义理论增添了耀眼的光芒。

\section{三、《宣言》蕴涵着丰富的人学思维}

马克思主义的人学思维虽然没有明确的定义, 但贯穿在众多的文本之中。 该人学思维始终围绕着 “现实的人” 这一原点, 坚定地把 “人” 设定为历史 发展的根本主体，明确打破种种约束实现人之本性的彻底解放。《宣言》在 某种程度上足以被称作马克思主义的人学宣言, 对 “自由人联合体” 的分析 是它的逻辑归宿和实际旨归。该著作通过对资产阶级现实活动的非人性质的 分析, 批判资产阶级对人性的践踏, 形成了独特的人学视野, 并影响着马克 思其他思想的发展。

\section{（一）从重视人性培养的方面来说}

《宣言》中的人学思维, 一个突出的特点就是对人性的重视。此文本主 要通过批判资产阶级对人性的摧残等不良现象, 来阐述无产阶级对人性培养 的特殊关注。

首先, 揭露资产阶级无视人性, 肆意践踏。《宣言》认为资产阶级破坏 了之前的封建伦理观念，同时以 “自由、平等” 等看似高尚的词语来代替之。 但是, 资产阶级所谓的自由、平等并没有现实意义, 只是为了维护自身统治 的口号而已。正如《宣言》中说道的: “它把人的尊严变成了交换价值, 用 一种没有良心的贸易自由取代了自力挣得的自由” ([1], p.3)。资本主义的社会 到处弥漫着利已主义的迷雾，生活在此状态下的人们不可能实现真正的自由 平等。高度市场化、功利化的社会环境, 造成了人际关系的疏远、冷漠、无 涉和隔阂, 这也是资产阶级矛盾重重的基本原因。“在资产阶级社会里, 资 本具有独立性和个性，而活动着的个人却没有独立性和个性” [2]。资本成为 资产阶级社会中的主体，原本独立、活泼的人竟成了资本的傀佃。“资本主 义披着发展人性的外衣，实质上却压迫人民对资本的专制统治俯首称臣”([1]， p.30)。资产阶级撕下了罩在家庭关系上的温情脉脉的面纱，把这种关系变成 了纯粹的金钱关系。至此，建立在金钱之上的人性，早已被践踏得不堪入目。

其次，正视人性的彰显，表现人道的关切。《宣言》聚焦于人的具体现 实的活动，直面资产阶级针对人性问题的片面性和孤立性，展示出无产阶级 的现实生存际遇, 在人学的传播中时刻正视彰显人性。该著作表明必须使用 废弃践踏人性的私有制的过渡手段，才能促成人作为人的本质，拯救人的独 
立性和主体性。通过不断提高社会经济发展水平, 保障人们平等、自由践行 价值追求的举动去逐步消灭阶级对立和阶级本身, 在此基础上走向共产主义, 实现人性最大水平的发挥, 这也是无产阶级的最高奋斗目标和价值追求。《宣 言》始终贯彻人性的思维, 这也为我们更好地理解马克思的人学思维提供了 全面的材料，同时为实现人的自由解放和全面发展贡献了基础性的指导作用。

\section{（二）从关注人的发展价值的方面来说}

《宣言》始终坚守从个体出发考虑全体进步的基本精神, 因此提出要以 “每个人的自由发展” 为条件去实现 “一切人的自由发展”。该著作对人之 价值的关注主要表现为 “人的解放” 和 “人的自由全面发展” 两个方面。

首先, 重视人的解放。资产阶级生存和统治的根本条件, 是财富在私人 手里的积累, 是资本的形成和增殖, 雇佣劳动是资本的极大条件。[3] 与资产 阶级形成鲜明的对比, 无产阶级想要成功地争夺政权, 最终实现共产主义社 会, 就必须完全摒弃资产阶级的自私与苛刻, 勇于打破雇佣的枷锁。因此, 马克思在《宣言》中提出 “人的解放” 的号召来解救处于水深火热的劳苦大 众。与此同时, 他还一针见血地指出了人类解放和政治解放的区别, 全面分 析了二者的互促互动关系。就马克思主义的视角而言, 政治解放旨在利用革 命的方式把政权牢牢把握在无产阶级手中, 为自身夺取彻底的政治权利和政 治自由; 人类解放则是指在政治解放的基础上，从世俗的枷锁束缚中解放出 来获得充实的精神自由, 实现自身精神层面的追求。如此说来, 政治解放是 实现人类解放的基础, 人类解放是更高层次的政治解放。正如马克思在《宣 言》中所讲: “要不是每一个人都得到解放, 社会本身也不能得到解放。” ([4], pp.322-323)这也就是说, 马克思主义所提倡的人的解放肯定不是资产阶 级的形而上学式的假惺惺, 仅仅是少数人得到利益满足的狂欢, 而是在每个 人都得到解放基础上的踏踏实实的 “全人类的解放” 。马克思毕生追求的共 产主义社会正是在 “全人类的解放” 得以实现的社会形态。生活在这样社会 形态的人类已达到彻底解放的状态, 最大多数人的利益能得到全方位地保障, 完全粉碎了以放弃多数人利益的方式来满足少数人特权的畸形社会。《宣言》 中凸显人之解放的重要性和急迫性, 实现人的解放是共产党人的价值追求。 实际上, 只有打破囚禁大众的桎梏去追求每个人的解放, 才能达成人的自由 全面发展。

其次, 追求人的自由全面发展。人的自由全面的发展是马克思主义的重 要命题, 也是实现人的现代化的根本目标。[5]马克思主义人学思维在《宣言》 中最重要的体现就是人的自由全面发展的论断, 推进人的自由全面发展是一 个不可逆转的过程。实现人的自由全面发展符合唯物史观的方法论要求, 体 现了社会客观规律性与人的主观目的性相统一的特征。马克思在《宣言》中 用了大量的篇幅解释了其所要寻求的人的自由全面发展囊括的具体内容, 主 要包括这样几个层次: 一是人类劳动实现自由, 二是人在自然界中重获自由, 三是人们在社会生活中创造自由。[6]马克思主义所追求的是人的 “自由发 展”, 认为存在于社会现实中的活生生的个人是发展的主体。这种 “自由发 展” 要求人的个性、人格、创造性和独立性最大限度地 “不受阻碍的发展” 。 
[7] “自由发展” 是 “全面发展” 的前提, 如果一个人的 “自由发展” 都不可 能实现，那么何谈 “全面发展” 呢？同时，马克思主义所寻求的是人的 “全 面发展” , 既是人的本性、本领的协调发展, 也是人的天然本质、社会本质 和精神本质的共同提高，还是人的经济、政治、文化等其他各领域实际权利 的真确实现。因此, 马克思首创性地提出哲学家们不应该只是停留在理论上 的解释世界, 更需要深入实践去改变世界这一推论。在他看来, 实现人的自 由全面发展也需要落到实处, 以无产阶级运动的方式塑造创造美好生活的主 体，即自由的、发展的人。

\section{四、《宣言》中人学思维的时代价值}

《宣言》中讲述的人的自由全面发展等人学思维有巨大的理论和实践意 义。列宁曾如此评论《宣言》的重要地位：这部著作以天才的透彻而鲜明的 语言描述了新的世界观。[8] 该著作蕴涵的科学理论为无产阶级和共产党人认 识世界和改变世界提供了一盏明灯, 其中阐释的新世界观是工人运动高涨的 根本所在。《宣言》彰显的人学思维已经成为马克思主义者毕生为之奋斗的 人生理想和社会目标，特别是上文提到的人的解放、人的自由全面发展更是 凝练成他们对人学进行深刻认识的成果。

\section{(一) 理论价值}

在马克思主义发展的历史长河中, 《宣言》始终是一座里程碑式的著作, 其中的人学思维内容丰富、博大精深。它从根本上体现了对人类的终极关怀, 对人类解放和全面发展的强烈关注。从联系的观点看，《宣言》中的人学思 维非但不是孤立存在的, 而是同科学社会主义的学说、社会主义的制度等不 可分割的, 自始至终都紧紧围绕着社会主义的运动进行理论上的思考。此外, 延续了一百多年的社会主义运动理论和实践的发展也表明了 “人” 在社会主 义建设中的重要地位, 再次验证了促进人的全面发展, 既是社会主义本质的 具体体现，也是社会主义建设的重要奋斗目标。

《宣言》中的人学思维充分说明人的解放和发展是科学社会主义运动的 终极目的, 滋养着中国式现代化建设的根本目标。为中国在不同时期理性处 理社会发展与人的发展的的关系，持续探寻实现人的全面发展的实效性办法; 为如何加快和谐社会的构建等现实问题提供了独特的思想指引。正是在这样 一份高屋建瓴的人学宣言的理论指导下, 以人民发展为中心的创新性理论才 能在中华民族开花结果，马克思主义中国化才能实现一次次的飞跃。即便是 在如今洋溢着新气象的时代, 延续马克思主义人学思维的中国化发展仍然是 我们不解的追求, 是中国共产党坚定 “以人为本” 治国理念的根基, 也是中 国人民进行社会主义现代化建设和实现 “中国梦”的理论导航。

\section{(二) 实践价值}

《宣言》中的人学思维从现实社会的具体领域和活动去关怀人性、人学, 把人学研究的逻辑自觉与无产阶级的现实运动相结合, 使人学视野获得开放 式发散, 并有着现实的的依。恰如 “两个必然” 总结论, 诚然是工人阶级和 
资产阶级斗争的直接结果, 但更是生产力发展的客观规律和必然要求。[9]在 已大步踏上第二个百年奋斗目标新赶考路的特殊背景下，中国更要加紧生产 力的发展, 继续挖掘《宣言》人学思维的实践价值, 以 “两个必然” 结论引 领人的自由全面发展之追求。从现实情境看, 不论是直面抗击新冠肺炎疫情 的 “大考验” ，还是宣告第一个百年奋斗目标的实现；不论是中国人民在中 国共产党的根本领导下创造出源源不断的中国奇迹，书写了一幕幕中国式的 精彩篇章, 还是新时代的中国人切实得到前所未有的全面发展等等, 都是马 克思主义的人学思维在华夏大地锃铭有力的践行, 都是《宣言》中的人学思 维实践价值的体现。

\section{五、结语}

立足当下成绩, 展望未来走向, 马克思主义的人学思维必将继续发挥它 不可置疑的时代价值。《宣言》蕴涵着的丰富的人学思维从理论角度为新时 代中国的再创辉煌筑牢根基, 以哲学政治经济学的思路为中国实现新飞跃赋 予扎实的支撑。习近平新时代中国特色社会主义思想作为马克思主义理论的 卷续发展，其中不负人民的理念适应了社会发展的要求，是对《宣言》中的 人学思维特别是人全面发展理论的守正创新。当下社会主义矛盾的变化, 人 们对精神需求的渴望更加强烈, 对自身的发展愈发重视综合性因素等等, 无 不表明马克思主义人学思维的现实性。一系列的现实成果也是在新时代继续 挖掘《宣言》人学思维研究价值的根本依据。

实践证明, 只有坚持正确的理论指导去真正关注人性的健全发展, 在中 国这片土地上不断深化马克思主义中国化的进程, 才能助力中国共产党这一 百年大党自觉汲取马克思主义发展史上的精神财富, 带领中国人民在 “两个 大局” 中加快 “两个结合”的步伐, 坚定迈向新的发展征程。

\section{Conflicts of Interest}

The author declares no conflicts of interest.

\section{References}

[1] 马克思, 恩格斯. 共产党宣言 $[\mathrm{M}]$. 北京: 人民出版社, 2017.

[2] 刘飞. 浅析马克思个体和共同体的历史辩证关系 [J]. 文史博览, 2016(12): 80-82.

[3] 陈文通. 深刻领会《共产党宣言》阐明的一般原理[J]. 中国浦东干部学院学报, 2018(5): 59-73+136.

[4] 马克思, 恩格斯. 马克思恩格斯全集(第 3 卷)[M]. 北京: 人民出版社, 1972.

[5] 奕淳钰, 白洁. 《共产党宣言》中“人的现代化”意蕴、特征及启示 [J]. 湖南社会 科学, 2021(5): 37-43.

[6] 范鹏, 甄晓英. 《共产党宣言》: 人民美好生活观的思想源头[J]. 甘肃社会科学, 2021(6): 27-34.

[7] 贾秀梅. 和谐社会：科学社会主义核心价值观的回归[J]. 山西大同大学学报, 2016(3): 1-3+7.

[8] 靳辉明. 《共产党宣言》的理论价值及当代意义 [J]. 马克思主义理论学科研究, 2018(1): 13-20. 
[9] 李雯帆, 刘明华. 百年大党对《共产党宣言》精神的春续与创新 [J]. 理论视野, 2021(10): 11-16.

\section{Appendix}

\section{浅析《共产党宣言》中的人学思维}

摘要: 《共产党宣言》(以下简称《宣言》) 是国际共产主义运动的纲领性文 献, 标志着马克思主义的诞生, 是对人类社会变革和思想革命影响最为深远 的著作之一, 蕴涵着丰富的人学思维。在了解《宣言》创作背景的基础上, 深入探究该文本对人性问题的重视和对人之自由全面发展的关怀, 思考其中 的马克思主义人学思维在中国的具体运用，有利于为中国当下的发展提供重 要的现实启示, 有利于创新开辟中国式的现代化发展道路, 激发中国特色社 会主义事业渐进取得新的飞跃。

关键词: 《共产党宣言》, 人学思维, 中国式现代化, 时代价值 